\title{
Production of Beauveria bassiana Air Conidia by Means of Optimization of Biphasic System Technology
}

\author{
Vladimir Gouli, Svetlana Gouli* and Jae Su Kim \\ Plant and Soil Science Department; University of Vermont - USA
}

\begin{abstract}
Air conidia production of Beauveria bassiana, strain CA-603 was studied based on modified diphasic system. The biomass yield obtained in the first phase based on submerged cultivation of fungus was processed using methodology providing different contact with air space. Our study indicated that productivity of the second stage of diphasic system is had inversely proportional dependence on depth of liquid fungal biomass. Increase of biomass depth is significantly decreased production of air conidia. Two methodology of biomass processing extending contact biomass with air space including distribution of fungal material on surface of hygroscopic paper and starch packaging peanuts were investigated. The novel substrates provided optimal contact between the submerged fungal biomass and the air, and overall, conidial production was directly proportional to the total area of air-to-fungal surface. Technologies based on the starch peanuts and hygroscopic paper were the most productive in comparison to the common technology where the submerged culture was transferred to flat containers. The advantages and disadvantages of these different production methods are discussed.
\end{abstract}

Key words: Beauveria bassiana, aerial conidia, biphasic production technology, starch peanuts, roll-method

\section{INTRODUCTION}

Entomopathogenic and antagonistic fungi are important natural control agents that limit numerous noxious organisms, and many important pest problems can be remedied based on these microorganisms. Presently, fungi are considered to be very important microbial pesticides (Ferron 1985; McCoy 1990; Goettel et al. 1995; Humber 2000; Lacey et al. 2001; Gouli and Prishepa 2006), and there are numerous formulations for the control of different pests including; phytopathogenic microorganisms, noxious nematodes, mites and insects (Kabaluk and Gazdik 2005). The most well-known formulations are based on antagonistic species from the genera Trichoderma, Gliocladium, Coniothyrium and entomopathogenic species from the genera
Beauveria, Metarhizium and Lecanicillium. Production and formulation technologies for these fungi have been based largely on their aerial conidia form or on their submerged blastospores (Kleespies and Zimmermann 1992; Burges 1998; Deshpande 1999; Vu et al. 2008; GandarillaPacheco et al. 2012). In general, however, fungal formulations for pest control contain aerial conidia as the active and most stable ingredient. The traditional fermentation equipment used in industrial microbiology is based largely on the submerged cultivation of microorganisms and it is not well-suited for the mass-production of the aerial conidia of fungi. Instead, cultivation on solid substrata is required for optimal yields, thus alternative technologies for the mass-production of microorganisms as biocontrol agents have been developed over the past hundred years. Currently,

*Author for correspondence: sgouli@uvm.edu 
there are two principal industrial mass-production technologies, each with numerous modifications. The first is a two-stage procedure or biphasic system, where the fungus is first cultivated as a submerged culture and then is transferred to flatbottomed containers for additional growth and sporulation. This type of technology is defined as a combined method (Sikura and Primak 1970) or diphasic production system (Kassa et al. 2008) where after a defined period the fungus forms a superficial film of mycelia and aerial conidia. The film is then dried and formulated. This technology was first developed at the Ukrainian Research Institute of Plant Protection (Telenga and Goral 1966; Sikura and Primak 1970). The method has long-been employed because it is results in pure fungal propagules, unfortunately there is limited information relating to certain technological details. Logically, the depth of the liquid biomass in the production unit should significantly influence the formation of aerial conidia, where a thin layer of biomass provides the maximum conidial production because only the upper part of the material has optimal contact with the air. Currently, only old publications on Russian and Ukrainian have addressed this issue (Zacharshenko et al. 1963; Telenga and Goral 1966). The twostage method suffers from the disadvantages that it is not highly productive, it demands a large area for production and special care must be taken to prevent microbial contamination. The second type of technology is based on various solid substrata including grains such as sorghum, rice, wheat, and millet. For this method, the sowing material is first prepared and then inoculated on the substratum which provides the optimal physical parameters for cultivation. The method is sometimes also termed as biphasic system. However this is not accurate because the first step is related to the preparation of the sowing material which can be achieved using either submerged or solid substrate cultivation. Using this method, a satisfactory quantity of conidia per unit of substratum can be achieved and this technology is widely uses in different countries (Taborsky 1992; Feng at al. 1994; Jenkins et al. 1998; Inglis et al. 2001; Leite et al. 2002; Machado et al. 2010). The main advantage of using a grain substratum lies in its productivity; however there are two difficulties in implementing this technology. First of all, preliminary processing and sterilization of grain is a power-and labour consuming process. In addition, the separation of the conidia from the substratum requires additional effort.

There have been ongoing efforts to develop new and better technology for the mass-production of hyphomycetous fungi. In particular the special "roll-method" was proposed for both the massproduction and application of fungi for pest control (Gouli and Gouli 2007; Gouli et al. 2011). The method is based on the use of double-layer rolls and has opened a new possibility for the effective production and application of entomopathogenic and antagonistic fungi for pest control. This method was proposed in concert with an improved variation of the two-stage method using starch packaging material (starch peanuts) for increasing the aeration of the biomass and absorption of the fungal metabolites (Gouli et al. 2008).

The goal of the research herein is to compare different modifications of the biphasic system technology as it relates to the production of the fungus Beauveria bassiana.

\section{MATERIALS AND METHODS}

\section{Fungal strain and submerged cultivation of the fungus}

A single strain of the entomopathogenic fungus Beauveria bassiana, CA-603, was used for all experiments. This strain was isolated from soil collected in an avocado plantation in California, and is deposited in both USDA ARS and University of Vermont Collections of Entomopathogenic Fungal Cultures. Fungal culture from long-storage at $-80^{\circ} \mathrm{C}$ was short-term activated at $45^{\circ} \mathrm{C}$, and then was cultivated using standard Potato Dextrose Agar (PDA) medium at $22 \pm 2^{\circ} \mathrm{C}$ for 12 days. Conidia for submerged cultivation were harvested from plates in a sterile aqueous solution of $0.01 \% \quad(\mathrm{v} / \mathrm{v}) \quad$ Silwet-77 (Loveland Industries, Greeley, CO) and adjusted to $5 \times 10^{7}$ conidia $\mathrm{mL}^{-1}$ using a hemocytometer. A 2 $\mathrm{mL}$ aliquot of this suspension was then used to inoculate $500 \mathrm{~mL}$ Erlenmeyer flasks with $100 \mathrm{~mL}$ Potato Dextrose medium which were incubated at $14^{\circ} \mathrm{C}$ and $150 \mathrm{rpm}$ for $71 \mathrm{~h}$ on an Exella E24 Incubator Shaker (New Brunswick Scientific, NJ). After $72 \mathrm{~h}$, a $1 \mathrm{~mL}$ sample was taken from each flask to determine the concentration of the blastospores. The fungal biomass obtained after submerged cultivation in flasks was adjusted to 
$1 \times 10^{8}$ blastospores $\mathrm{mL}^{-1}$ using sterile distilled water, and further processed for the production of aerial conidia using the traditional biphasic system method, the method based on starch granules and the novel "roll method".

\section{Traditional biphasic system}

The liquid biomass from the submerged cultivation was transferred to stationary plates for the production of aerial conidia. Four different depths of biomass were investigated for the production of aerial conidia; $2.5,5,10$, and 15 $\mathrm{mm}$. The respective volumes to obtain these depths in standard sterile $100-15 \mathrm{~mm}$ diameter Petri dishes were 12.5, 25, 50, and $75 \mathrm{~mL}$. Dishes were incubated at $24^{\circ} \mathrm{C}$ for 14 days in an aerated plastic box to prevent desiccation of the material. After 14 days, the fungus formed a surface film with aerial conidia. Conidia were harvested by flooding each film with $100 \mathrm{~mL}$ of sterile $0.02 \%$ (v/v) Silwet-L77 (Loveland Industries), and processed using a 10-Speed Blender (Osterizer) at high speed for $2 \mathrm{~min}$. Conidial yields were obtained as previously described. All treatments were replicated five times within an experimental replicate, and the entire experiment was repeated three times.

\section{Technology based on starch peanuts}

A total of $10 \mathrm{~g}$ of starch peanut packing material was evenly distributed inside thermo resistant polypropylene bags. The starch material inside the bags was covered with a $10 \%$ whey powder suspension (Agri-Mark Inc., Middlebury, VT) in ethanol using a manual sprayer to prevent the rapid destruction of starch after contact with the liquid fungal material. After drying, the material in the bags was sterilized using a microwave oven (Dural Wave Microwave System, General Electric) for $10 \mathrm{~min}$. While microwaving, the plastic bags were held over a container filled with water to prevent damage of the sterilized material. After sterilization the starch material was treated with the fungal biomass. Three doses of inoculum were used for treatment; 10,50 , and $100 \mathrm{~mL}$. The inoculated material was then incubated at $24^{\circ} \mathrm{C}$ for 14 days. The sporulated fungal biomass from each plastic bag was homogenized with 1 litre of $0.02 \%$ (v/v) Silwet-L77 in a blender for $2 \mathrm{~min}$. Ten $\mathrm{mL}$ of this was further diluted 10 times, and the number of conidia calculated.

\section{Roll production system}

Double-layered rolls were used as the cultivation unit for the liquid fungal biomass to obtain aerial conidia. The inner layer was hydroscopic paper (Bounty Regular Roll, width $28 \mathrm{~cm}$ ), and the external layer was bubble packing material (United States Postal Service ${ }^{\circledR}$, product Code 93009208, roll width $40 \mathrm{~cm}$, bubble diameter 9.5 $\mathrm{mm})$. This external layer allowed for air circulation within the rolls. The total length of the rolls consisted of $140 \mathrm{~cm}$ the hydroscopic paper (five perforated sheets of $28 \times 28 \mathrm{~cm}$ ), and a corresponding length of the bubble packing material. The fungal biomass after submerged cultivation was uniformly distributed among the paper at a rate of $250 \mathrm{~mL}$ per roll or $50 \mathrm{~mL}$ per perforated sheet (Fig.1). This volume of biomass was determined to be optimal based on the adsorption properties of the paper used.

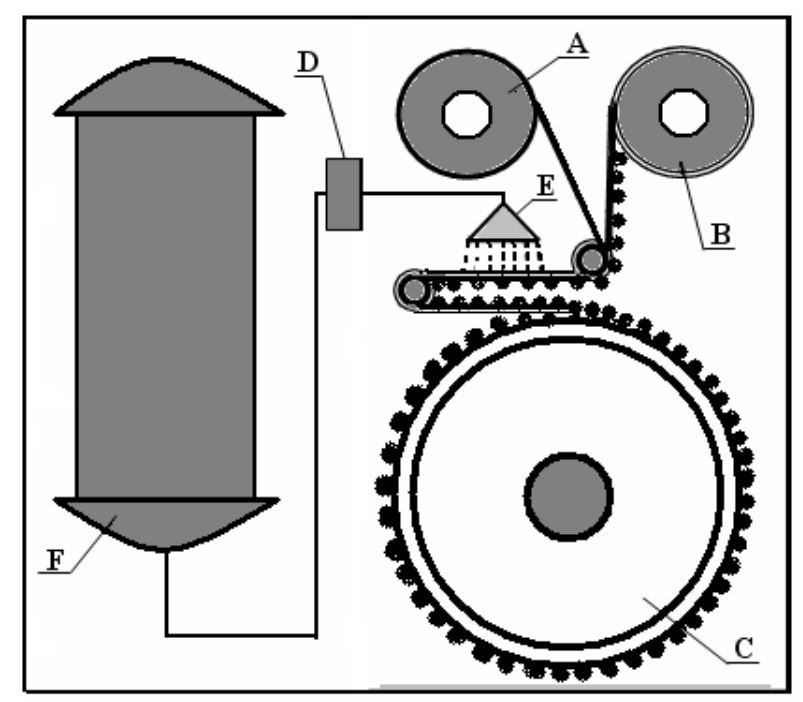

Figure 1 - Principal diagram of the Roll-method for the production of fungi: A - paper roll; B - roll of bubble packing material providing roll aeration; $\mathrm{C}$ - inoculated carrier; D - dosator of fungal biomass; E - sprayer; F bioreactor.

Inoculated rolls were placed in plastic bags fitted with perforated ventilation on both the top and bottom. The cultivation units were incubated vertically at $24^{\circ} \mathrm{C}$ for 14 days. The number of aerial conidia on the hydroscopic paper were counted by individually flooding sheets with 1 liter of $0.02 \%$ (v/v) Silwet-L77, blending for 2 minutes, and counted as previously described. 


\section{Viability evaluation}

The conidia viability was estimated after drying the sporulated fungal biomass. Suspensions of conidia in water were adjusted to $10^{6}$ conidia $/ \mathrm{mL}$ and distributed on the surface of PDA medium in an $8.5 \mathrm{~cm}$-diameter Petri dish. The inoculated material was incubated for a period of $20 \mathrm{hs}$ at $20 \pm 2^{\circ} \mathrm{C}$, after which, the area necessary for the calculation of the percentage of germinated conidia was fixed using lactophenol stain and covered by a glass coverslip. The viability was evaluated by calculating the number of germinated conidia out of 100 for four different areas of the Petri dish for each production unit.

\section{Data analysis}

The conidial yields were analyzed by variance (ANOVA) followed by Duncan's multi range test (MRT) $(p<0.05)$ using SPSS ver. 17.0 (SPSS Inc., USA, 2009). In addition, Pearson's correlation tests (two tailed) were conducted using the data in Figure 2 and 3 to examine the dosagedependant response and finally, general linear model (GLM) followed by Duncan's MRT $(p<$ 0.05 ) was conducted as an overall comparison of the data (Fig. 4).

\section{RESULTS AND DISCUSSION}

\section{Depth of biomass and conidia harvest based on biphasic system}

In all methods tested, the fungal biomass obtained from submerged cultivation produced a mycelial film containing aerial conidia on surface of the cultivation units after two weeks of processing. The number of aerial conidia produced in the Petri dishes based on traditional biphasic system was found to be negatively correlated with the depth of liquid biomass (Coefficient of Pearson correlation $=-0.822^{* *}, N=60$, two-tailed; $* *=$ significant at the 0.01 level) (Fig. 2). At the lowest depth of the liquid biomass treatment $(2.5 \mathrm{~mm})$, the conidial productivity was $4.2 \times 10^{7}$ conidia. $\mathrm{mL}^{-1}$, and was the best among all of the pan treatments $(F=70.3$, $\mathrm{df}=3,59, P<0.001$ ).

In general, an increase in the depth of the liquid biomass in the cultivation container led to decrease in the yield of aerial conidia per $\mathrm{mL}$ of initial fungal biomass (Fig. 2).

The yield obtained from a minimal depth of 2.5 $\mathrm{mm}$ was 1.5, 11, and 13-fold greater than depths of 5,10 , and $15 \mathrm{~mm}$ respectively. This minimal depth was determined to be the optimal depth of biomass for the greatest production of conidia using the four tested parameters. Consequently, the technology of using liquid biomass independent of a secondary support for conidiation was reliant on volume to air contact. A depth of $2.5-3 \mathrm{~mm}$ was the minimum that could be used for the PDA medium in the flat containers, owing to the surface tension of the biomass after cultivation.

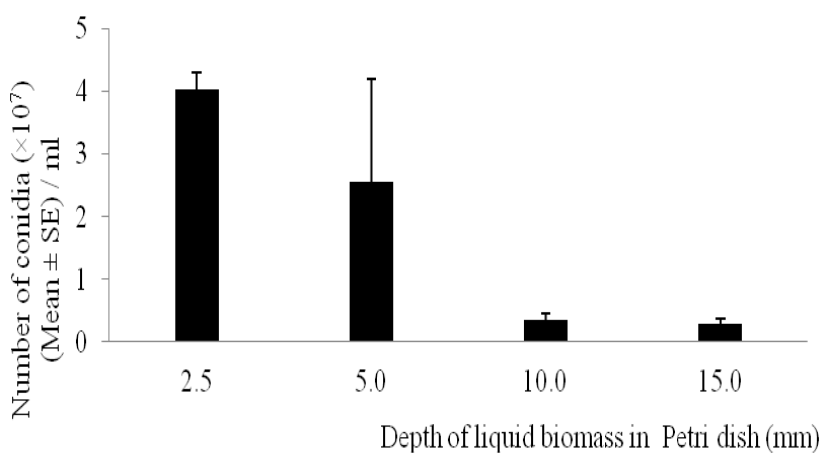

Figure 2 - The number of Beauveria bassiana conidia (Mean \pm SE) produced in different depths of liquid biomass in Petri dishes.

\section{Conidia production based on starch peanuts}

The starch peanuts used were found to better support the contact between the mycelial biomass with the air. A volume of $10 \mathrm{~mL}$ of biomass per 10 $\mathrm{g}$ of starch peanuts did not destroy the peanuts, while 50 and $100 \mathrm{~mL}$ partially-, and completely degraded the structural-integrity of the peanuts respectively. In general, the yield of aerial conidia was dependent of the structural condition of the starch peanuts, and the number of conidia produced was negatively correlated to the volume of liquid biomass used (Coefficient of Pearson correlation $=-0.911^{* *}, N=45$, two-tailed; $* *=$ significant at the 0.01 level). In the lowest depth of the liquid biomass treatment $(2.5 \mathrm{~mm})$, the conidial productivity achieved $4.2 \times 10^{7}$ conidia/mL, the best among the treatments $(F=$ 70.3 , df $=3,59, P<0.001)$. The highest conidial yield $\left(7.0 \times 10^{8}\right.$ conidia. $\left.\mathrm{mL}^{-1}\right)$ was observed when $10 \mathrm{~mL}$ of biomass treatment was used along with the lowest amount of biomass $(F=127.1, \mathrm{df}=2$, $44, P<0.001)$. This volume of inoculum for $10 \mathrm{~g}$ of starch peanuts resulted in the greatest number of air conidia per $\mathrm{mL}$ of initial material (Fig. 3).

The experiments with the starch peanuts confirmed that the production of aerial conidia from submerged fungal biomass inoculum was 
dependent on biomass-air contact. The two-stage method and the novel technology based on starch peanuts show same pattern - the thinner the liquid biomass layer, the greater the yield of aerial conidia. The productivity of the first and second technology cannot be directly compared because the fungus received additional nutrition in the latter case in the form of the whey powder that was used to preserve the structural integrity of the starch peanuts during sterilization.

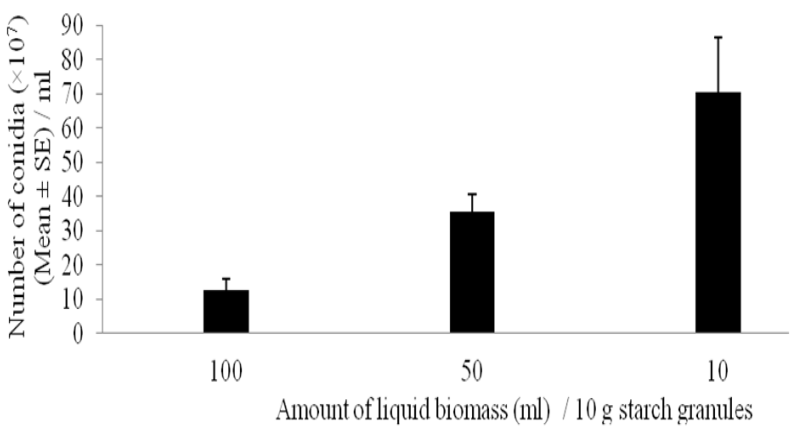

Figure 3 - The number of Beauveria bassiana conidia (Mean \pm SE) produced in the different amounts of liquid biomass per $10 \mathrm{~g}$ of starch peanuts.

\section{Conidia production based on roll system}

The roll production system provided the maximal contact between the fungal biomass and the air. One standard roll of the Bounty Regular Roll (total area: $784 \mathrm{~cm}^{2}$ ) was capable of supporting $50 \mathrm{~mL}$ of liquid fungal material. This volume is impossible to uniformly distribute among the nonhygroscopic surface of the flat containers used in the first methodology due to the surface tension of the liquid. The productivity of the roll production system was similar to the highest conidial yields obtained using the starch peanut method. The number of conidia produced using $50 \mathrm{~mL}$ liquid biomass per unit of paper was $4.9 \times 10^{8}$ conidia.mL $\mathrm{mL}^{-1}$ (Fig. 4). This was not significantly different from the yield of the conidia obtained from $50 \mathrm{~mL}$ of inoculum using starch peanuts as the biomass-air support $\left(\chi^{2}=2.0, \mathrm{df}=28, P=\right.$ 0.053 in 2-sample t-test; $F=4.1, \mathrm{df}=1,28, P=$ 0.053 in ANOVA).

Overall, the starch peanut medium incorporated with $10 \mathrm{~mL}$ liquid biomass was superior to the other treatments in the conidial productivity $(F=$ 87.6, df $=7,118, P<0.001$ ) (Fig. 4). In this overall treatments, no less significant was found within the culture method $(F=87.4, \mathrm{df}=2,112, P$ $<0.001)$ and the amount of liquid biomass inoculated $(F=41.5, \mathrm{df}=5,122, P<0.001)$.

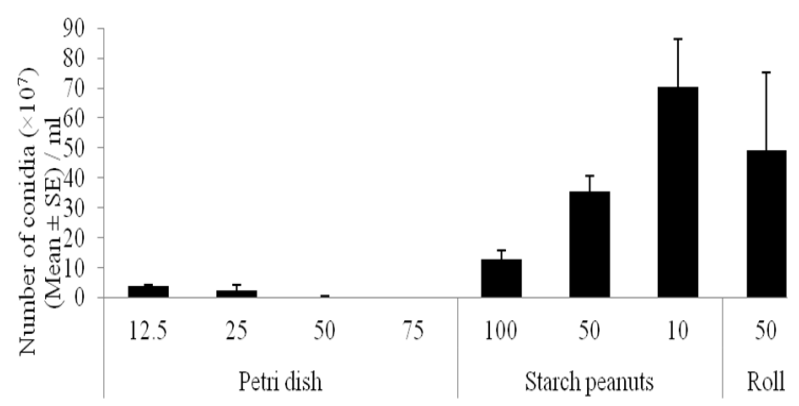

Amount of liquid biomass (ml) per cultivation unit

Figure 4 - The number of Beauveria bassiana conidia (Mean \pm SE) produced in the rolling papers (left) and the starch granules (right) inoculated with $50 \mathrm{~mL}$ of liquid biomass per cultivation unit.

All of the systems tested in this study were found to be suitable for obtaining aerial conidia, and can be used for practical application along with the common technology based on different types of grain. The traditional biphasic system technology has received the greatest attention to-date as this technology provides pure conidia without additional particles from the substrate used, making the product immediately suitable for spray application formulations. In the case of the biphasic system technology, relatively-high conidial yields can be achieved only when a thin layer of the fermentation material is used. This demands a large area for industrial production, which is labour-consuming for the protection of the cultivation material from microbial contamination. The second stage of the two stage technology can be achieved under non-sterile conditions (Sikura and Primak 1970); however this approach can result in dangerous contamination of the final products, particularly in the case of the mass-production of different fungal formulations in the same industrial facility.

The technology based on the starch peanuts has several advantages in comparison with the common two-stage technology. First of all, this technology results in a significantly higher yield of conidia. In addition, the starch peanuts absorb the fungal propagules along with their metabolites. As a result, this technology meets all of the necessary preconditions for increasing the insecticidal 
activity of formulations using the starch peanuts technology. The starch forms a liquid gel in water, allowing for it to be used in spray equipment for application of the starch-based formulations.

Conidia production based on roll system gives the fungal material associated with hygroscopic paper. Fungus colonizes both sides of paper including zones contacting with plastic babbles. The conidia can be easily separated from the paper carrier. For instance, the layer can be rinsed with a liquid, such as water, used to prepare the suspension for application to the environment. Because the layer can be directly implemented during preparation of the suspension, the interaction of people working with the fungi is significantly reduced. By reducing the interaction between workers and the infective units, a system and/or method similar to those discussed above reduces any health risks that might be prevalent. Moreover, the paper having the infective units could also be used directly. Examples of these possibilities include, but are not limited to, pest traps; tapes and other applicators for plant roots, stems and tree trunks; and for other types of soil inoculators.

\section{Conidia viability}

The viability of $B$. bassiana conidia obtained using different variation of biphasic technology did not have significant differences and this index was fluctuated from $91.2 \pm 2.2 \%$, to $92.4 \pm 1.1 \%$.

\section{CONCLUSION}

Based on conducted research the possibility to significantly increase effectiveness of the biphasic system in case of production of $B$. bassiana air conidia was demonstrated. Enlarging contact area of liquid fungal biomass in the period of the second phase of cultivation led to the most intensive sporulation of fungus. As a result, the productivity of fungus is significantly increased. Expansion of the contact area is linked with minimization of the liquid biomass depth. There are different methods for enlargement of the contact area of fungal biomass and minimization of biomass depth but the most effective method is connected with distribution of a liquid suspension of fungal propagules on hygroscopic material like special paper or fabric. Several problems have arisen in case of realization of this possibility including difficulties with the prevention of contamination, avoidance of premature drying, the necessity for big industrial area etc. The greater part of the problems can be solved based on use of the Roll-method which provides the maximum harvest of air conidia and at the same time helps to avoid all enumerated problems. The Roll method of production of fungi provides a way to realize the mechanization and automation of technological processes. In addition, the method can simplify formulation and application of fungal material both as spray of plant canopies and incorporation in soil.

\section{ACKNOWLEDGMENTS}

This research was supported by the US Department of Agriculture, Agricultural Research Service, Cooperative Agreement 58-1907-5-521.

\section{REFERENCES}

Burges HD. Formulation of mycoinsecticides. In: Burges HD (ed.), Formulation of microbial biopesticides: beneficial microorganisms, nematodes and seed treatment. Kluwer Academic Publishers, Norwell, MA; 1998, 131-186.

Deshpande MV. Mycopesticide production by fermentation: potential and challenges. Critical Rev

Microbiol. 1999; 32: 229-243.

Feng MG, Poprawski TJ, Khachatourians GG. Production, formulation and application of the entomopathogenic fungus Beauveria bassiana for insect control: current status. Biocontrol Sci Technol. 1994; 4(1): 3-34.

Ferron P. Fungal control. In: Kerkut GA, Gilbert LI, editors. Comprehensive insect physiology, Biochemistry and Pharmacology, Pergamon Press, Oxford; 1985: 313-346.

Gandarilla-Pacheco FL, Arevalo-Niño K, Galan-Wong LJ, Coronado CFS, Quitero-Zapata I. Evaluation of conidia production and mycelial growth in solid culture media from native strains of entomopathogenic fungi isolated from citrus-growing areas of Mexico. Afr J Biotechnol. 2012; 11(79): 14453-14460.

Goettel MS, Johnson DL, Inglis GD. The role of fungi in the biological control of grasshoppers. Can J Botany. 1995; 73(1): 1-75.

Gouli VV, Prishepa LI. Global dynamics of research and technological works on mycopesticides. In: Plant protection: Proceedings: Contributed papers; 2006 March; Minsk, Belarus; Republican Scientific Unitary Company Institute of Plant Protection; 2003: 456-461. 
Gouli VV, Gouli SY. Roll-method for mass-production of hyphomycetous fungi. In: $40^{\text {th }}$ Annual Meeting of the Society for Invertebrate Pathology: Proceedings: Program-abstracts; 2007 Aug; Quebec City, Canada: p. 84 .

Gouli VV, Gouli SY, Parker BL, Kassa A. Utilization of a significant waste product for mass production of specialized insect-killing fungi for IPM. In: Vermont EPSCoR Annual State Meeting: Proceedings: Contributed abstracts; 2008 June; Burlington, USA, Vermont: University of Vermont: p. 28.

Gouli VV, Gouli SY, Parker BL, Skinner M. Shternshis MV. New method of mass-production of entomopathogenic fungi. In: International Conference for IPM: Proceedings: Contributed papers; 2011 July; Minsk, Belarus. p. 211-216.

Humber R A. Fungal pathogens and parasites of insects. In: Priest FG, Goodfellow M, editors. Applied Microbial Systematic. Dordrecht: Kluwer Academic Publisher; 2000. p. 199-227.

Inglis GD, Gottel TM, Strasser B. Use of hyphomycetous fungi for managing insect pests. In: Butt TM, Jackson C Magan N, editors. Fungi as biocontrol agents. Willington: $\mathrm{CAB}$ International; 2001. p. 23-69.

Jenkins NE, Heviefo G, Langewald J Cherry AJ, Lomer Ch. Development of mass production technology for aerial conidia for use as mycopesticides. Biocontrol News and Inform. 1998; 19(1): 21-31.

Kabaluk T. Gazdik K. Directory of microbial pesticides for agricultural crops in OECD countries. Agriculture and Food Canada; 2005.

Kassa A, Brownbridge M, Parker BL, Skinner M, Gouli V, Gouli S, Guo M, Lee F, Hata T. Whey for massproduction of Beauveria bassiana and Metarhizium anisopliae. Mycol Res. 2008; 112: 583-591.

Kleespies RG, Zimmermann G. Production of blastospores by three strains of Metarhizium anisopliae (Metch.) Sorokin in submerged culture. Biocontrol Sci Technol. 1992; 2: 127-135.
Lacey LA, Frutos R, Kaya HK, Vails P. Insect pathogens as biological control agents: Do they have a future? Microbial Control. 2001; 21: 230-248.

Leite LG, Batista-Filho A, Almeida JEM, Alves SB. Technical aspects of the industrial production of entomopathogenic fungi in Brazil. In: 35th Annual Meeting of the Society of Invertebrate Pathology: Proceedings: Contributed abstracts; 2002 Aug. Foz do Iguaçu, Brazil: Embrapa. p. 193.

Machado ACR, Montero AC, Almeida AMB, Martins MIEG. Production technology for entomopathogenic fungus using biphasic culture system. Pesq Agropec Bras. 2010; 45(10): 1157-1163.

McCoy CW. Entomogenous fungi as microbial insecticides. In: Baker RR, Dunn PF, editors. New directions in biological control: alternatives for suppressing agricultural pests and diseases. New York, USA. Alan R. Liss, 1990: v. 112. P. 139-159.

Sikura AI, Primak TA. Native formulation of Boverin. Microbiological Industry of Soviet Union, Department of Information, Moscow; 1970. P. 1-44.

SPSS Inc. Released 2009. PASW Statistics for Windows, Version 18.0. Chicago: SPSS Inc.

Taborsky V. Small-scale processing of microbial pesticides. FAO Agr Serv Bull. 1992; 96: 1-90.

Telenga HA, Goral BM. New method of cultivation of white muscardine on liquid nutrient media. In: Biological methods of pests control in agriculture. Tashkent, Uzbekistan: FAN publisher; 1966: 33-36

$\mathrm{Vu}$ VH, Hong S. Kim K. Production of aerial conidia of Lecanicillium lecanii 41185 by solid-state fermentation for use as a mycoinsecticide. Mycobiology. 2008; 36(3): 183-189

Zacharshenko N L, Primak TA, Goral VM. Semiindustrial production method of muscardine fungi in liquid nutrient media. In: Telenga NA, editor. Colorado beetle and new control method. Kiev: Dershsilgosvidav; 1963. p. 102-106. 